East African Journal of Science, Technology and Innovation, Vol. 2 (4): September 2021

This article is licensed under a Creative Commons license, Attribution 4.0 International (CC BY 4.0)

\title{
Toward improving household livelihoods using rain water harvesting technologies in Matungulu sub-county, Machakos, Kenya
}

\author{
1*WEKESA P M., 2NZIOKA J M., ${ }^{3}$ MUTUNE J M \\ ${ }^{1}$ Wangari Mathai Institute for Peace and Environmental Studies, University of Nairobi, Nairobi, Kenya \\ *Corresponding author: pwekesa@uonbi.c.ke
}

\begin{abstract}
Better utilization of rainfall through rainwater harvesting can greatly increase agricultural productivity, improve food security and alleviate poverty. Water is the main limiting resource for crop production in arid sub-Saharan Africa. The biggest challenge currently is growing water shortage and dwindling rivers. This has impacted the livelihoods of rural population in arid and semi-arid counties. The introduction of novel rain-water harvesting ( $\mathrm{RWH}$ ) is, however, seeking to mitigate the effects of perennial droughts in arid areas. Successful adoption of such technologies has the potential to alleviate water problems faced by rural households. In Kenya, very little research has been conducted about adoption of water harvesting technologies and their role in curbing water shortages. Therefore, there was a need to interrogate the extent to which adoption of water harvesting technologies has impacted households in Matungulu Sub-County. Focus group discussions, interview with key informants, and structured questionnaires were used to collect data for the study which were then analyzed using SPSS version 22 software. The findings indicated that overall, a composite mean of 4.04 and a standard deviation of 0.699 of the respondents agreed that incentives from the county government significantly promoted water harvesting technologies. This was confirmed by a positively strong and significant correlation between the integration of RHT in the county development agenda and the impact on household livelihoods. A further regression analysis indicated that Integration of RHT had a positive and significant influence on household livelihoods $(\beta=0.755, t=22.351$, $p=0.000<0.05$ ). Results of this survey indicate that rainwater technologies are financed mostly by household heads and county government initiatives have not been adequately felt. There is a strong indication from the study that water harvesting technologies had a statistically significant influence on the impact on household livelihoods. To ensure sustainability of rainwater harvesting technologies, the study recommends that Machakos County Government need to give continuous support, strengthen stakeholder and community participation in water management practices. Additionally, provide the necessary additional incentives to the community.
\end{abstract}

Keywords: households; harvesting; livelihoods; Rainwater; Technologies

Cite as: Wekesa et al., (2021). Toward improving household livelihoods using rain water harvesting technologies in Matungulu sub-county, Machakos, Kenya. East African Journal of Science, Technology and Innovation 2(4).
Received: $\quad 28 / 05 / 21$

Accepted: $\quad 26 / 08 / 21$

Published: $\quad$ 25/09/21

\section{Introduction}


A total of about 1.2 billion people cannot access clean and safe drinking water globally (Global Water Institute (GWI), 2013 Angoua et al., 2018; Armah et al., 2018). The demand for water use has grown globally outpacing population growth, and increasingly, many regions are currently nearing unsustainable water services levels, especially in arid regions (Barry et al., 2008; Baldwin et al., 2018; Biswas and Tortajada, 2019; Cherunya et al., 2015). According to Kerchof, C., 2016, under current trends, global demand for water will exceed supply by 40 per cent by the year 2030.

Many parts of the world are facing high to extreme water stresses with continued climate change effects (Bryan et al., 2018; Carrión-Crespo, 2011; Pradhan and Sahoo, 2019). This stress is due to scarcity of underground water, mismanagement of existing water bodies, increase in river water pollution, lack of water recycling, and wastage (Pradhan and Sahoo, 2019). Fresh and easily accessible water accounts for only $0.014 \%$ of all water on Earth leaving $97 \%$ of water as saline and slightly less than $3 \%$ as inaccessible (United Nations Development Programme (UNDP), 2006, Helmreich and Horn, 2009). Globally, in every six people, one or two people are water stressed, implying that they lack sufficient access to water (United Nations, 2015; Armah et al., 2018; Cherunya et al., 2015). In Africa, water scarcity is a reality with millions of Africans trekking long distances in search of water (Bancy M. et al., 2007; Armah et al., 2018; Cosgrove and Loucks, 2015).

About 41 percent of Kenya's population still relies on unsecure water sources, which include ponds, springs, water pans, wells, sand dams and rivers (Pradhan and Sahoo, 2019). Such challenges are common in rural areas and urban slums with piped water treated as a preserve of the affluent in society (GWI, 2013). In Kenya's arid and semi-arid lands (ASALs), the total demand for water often exceeds the water available to people and livestock. This problem is compounded by weak support from government and competition for resources amongst water users, which creates the potential for armed conflict (USAID, 2014). Matungulu Sub-County is a semi-arid region in Kenya that is prone to frequent droughts, water shortages and food insecurity (Machakos County Integrated Development Plan (MCIDP), 2015). It is not well documented how rain water harvesting technologies affect or influence livelihoods among households. Some of the rain water harvesting technologies utilized in Matungulu Sub County include: earth dams, water pans and roof top harvesting (MCIDP), 2015).

It has been established reliably from studies that rainwater harvesting technologies (RWHT) leads to a runoff retention of up to $87 \%$ and to double the infiltration (Tamagnone et al., 2020). Adopting RWHT makes it possible to extend the growing season hence enhancing the crop yield. These benefits contribute to the reduction of the climate-related water stress and the prevention of crop failure enhancing food security (Tamagnone et al., 2020).

According to Pradhan and Sahoo, (2019), the general objectives of rainwater harvesting are aimed at increasing the volume of water bodies, lessening flood and soil erosion, preventing overuse of underground water and saving money. Rainwater harvesting technologies, on the other hand, include: Roof top rainwater harvesting, rock and surface catchment systems, subsurface dams and sand dams among others (Pradhan and Sahoo, (2019).

The main objective of this study was to provide an understanding of the effects of rain water harvesting technologies on livelihoods in the study area. The specific objectives were to assess the barriers and enablers of utilization of rain water harvesting technologies among households; to assess the livelihood difference of households with water harvesting technologies and those without; to interrogate the extent to which Machakos County Government implements and integrates water harvesting technologies in its programs, planning and budgeting among households in Matungulu SubCounty in Kenya. This study would provide critical data on the household adoption of rain water technologies that can be used to develop key strategic plans on how to promote the use of RWHT through cost effective community initiatives to complement the county government efforts. 


\section{Materials and methods}

\section{The study area}

The study was conducted in Matungulu SubCounty, Machakos County. It borders Nairobi and Kiambu counties towards the West, Embu towards the North, Kitui towards the East, Makueni towards the South, Kajiado towards the
South West, and Murang'a and Kirinyaga towards the North West (MCIDP, 2015). Machakos County comprises of eight (8) constituencies also referred to as Sub- Counties including Machakos Town, Masinga, Kangundo, Yatta, Mavoko, Matungulu, Kathiani, and Mwala Sub-Counties (MCIDP), 2015) (Figure 1).

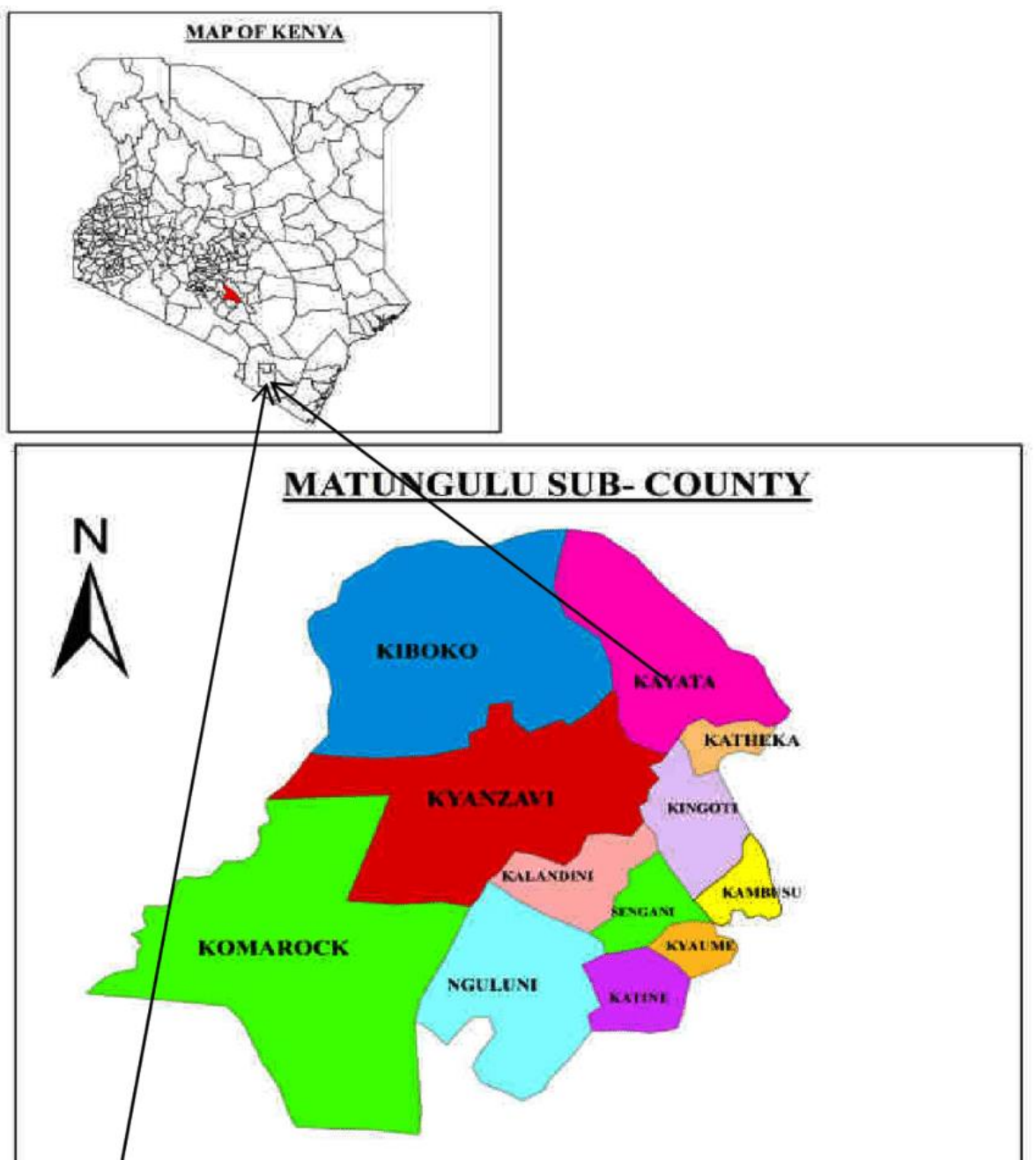

Figure 1. Map of Matungulu Sub-County

Source: Google Maps

The County has an altitude of $0^{\circ} 45^{\prime}$ to $1^{\circ} 31^{\prime}$ South as well as longitudes $36^{\circ} 45^{\prime}$ to $37^{\circ} 45^{\prime}$ East (MCIDP, 2015). The county's altitude is between 1000 - 1600 meters above sea level. Subsistence agriculture practices with Maize, sorghum and millet is common (MCIDP, 2015). Matungulu Sub- County comprises of Tala,
Matungulu East, Matungulu North, Matungulu West and Kyeleni Wards.

The local climate of Matungulu Sub-County is semi-arid with a few hilly terrains (MCIDP, 2015). The annual rainfall of the Sub-County is unevenly distributed and unreliable averaging between $500 \mathrm{~mm}$ and $1300 \mathrm{~mm}$. The short rains 
are experienced in October and December and long rains come in March to May. July is the coldest month while October and March are the warmest months with temperatures varying between $18^{\circ} \mathrm{C}$ and $29^{\circ} \mathrm{C}$ throughout the year. The total population of Matungulu Sub-County is 199,211 people, with 64,257 Households. It covered an area of 577.5 square kilometers with a population density is 215 persons per square kilometer dominated by the Akamba people (MCIDP, 2015).

Matungulu is part of Kenya's arid and semi-arid lands (ASALs), where the total demand for water often exceeds the water available to people and livestock. Competition for resources amongst water users creates the potential for armed conflict. Although Kenyans experience periods of severe water scarcity, annual rainfall is actually sufficient to support their livelihoods. The gap arises because a large portion of the water disappears unused through surface runoff, flooding and evaporation. A new approach is needed to unlock the potential of water sources, and use and manage them in a strategic and sustainable way.

\section{Sampling procedure}

This was estimated through the use of both primary and secondary data. Primary data collection involved use of a structured $\underline{Z^{2}} \mathrm{pq}$

$\mathrm{n}=\mathrm{d}^{2}$

$\mathrm{n}=384$ Households

Systematic sampling was done using probability sampling technique to select farm households from each of the two sub-locations. This sampling method was chosen since it had an advantage of giving all elements in any given population an equal opportunity of being included in the sample.

\section{Data analysis}

Data analysis was done using the Statistical Package for Social Sciences (SPSS version 22 software) mainly through descriptive statistics which included calculation of arithmetic mean, standard deviation, percentages and frequencies.

$$
y=a+\beta_{1}+X_{1}+e
$$

questionnaire to gather relevant information including respondents' bio data, barriers and enablers, RWT adopted, policy issues as well as impact on House Household Livelihoods.

Secondary data collection was based on time series data on food security and rain water harvesting. These data were obtained from statistical abstract reports, government publications such as the Machakos County Integrated Development Plan, 2015, Population and Housing Census Reports, Ministry of Agriculture Annual Reports and Food and Agricultural Organization (FAO) publications. These data was used to complement the primary data and to confirm mechanisms put in place by the county government regarding the use of WHT in the County.

A total of 384 households were considered in the study out of a total of 64,257 households residing in the area under study. The sample was calculated at 95\% confidence level, using Fisher's formulae, where (n) referred to the sample size (where the population being targeted was more than 10,000), (Z) was the standard normal deviation at the desired confidence level ( $Z$ level is 1.96 at $95 \%$ significance level), (p) is equal to 50 per cent, (q) is 1 - p while (d) is statistical significance level (0.05).

The analyzed data were then presented in tables and figures.

The regression models were used to test relationship between the independent and dependent variables on analysis of effects of rain water harvesting technologies among households in Matungulu Sub-County, Kenya. This was determined using the coefficient of determination. F statistics was applied to test hypothesis based on the study sample of 384 households.

The study hypothesis was tested using linear regression model stated below: 
Whereby:

$$
\begin{aligned}
\mathrm{y} & =\text { Impact on House Household Livelihoods } \\
\mathrm{a} & =\text { Constant } \\
\beta_{1} & =\text { Beta coefficient } \\
\mathrm{X}_{1} & =\text { Compute score Barriers and Enablers } \\
\mathrm{X}_{2} & =\text { Compute score Water Harvesting Technologies } \\
\mathrm{X}_{3} & =\text { Compute score Integration of RHT in County Development Agenda } \\
& \mathrm{e}=\text { error term } \\
Y_{1}= & \mathrm{a}_{1}+\beta_{1} \mathrm{X}_{1}+\mathrm{e}_{1} \\
\mathrm{Y}_{2}= & \mathrm{a}_{2}+\beta_{2} \mathrm{X}_{2}+\mathrm{e}_{2} \\
\mathrm{Y}_{3}= & \mathrm{a}_{3}+\beta_{3} \mathrm{X}_{3}+\mathrm{e}_{3}
\end{aligned}
$$

Matungulu Sub - County was chosen among other Sub - Counties in Machakos County because it is prone to frequent droughts and unpredictable short rains and RWH technologies were seen to be practiced amongst some households even though on small scale.

Validity and reliability of research instruments According to C.R. Kothari (2004), validity is the most critical criterion indicated the degree to which an instrument measures what it is supposed to measure. Bryman and Bell, 2015 defined validity as the degree to which information collection tools evaluate what they intended to do. Therefore, validity of the research instrument was properly tested through the pilot test, whereby a few respondents who were not included as part of the main study, responded well to the questionnaire. This helped in accepting new suggestions and amendments where necessary to obtain quality results.

Content validity was done by submitting the questionnaire to the relevant supervisors and experts to scrutinize, and rate each item's capacity in the tool providing expert judgment that was relevant and accurate for the research study. Before the actual research study commenced, piloting the tool also allowed the principal investigator to solve questions that needed more clarification. This process helped in validating the accuracy of the questions asked in the questionnaire and also in the achievement of the research objectives of the study.
The test of reliability is an imperative test of sound measurement whereby a measuring instrument is deemed reliable if it provided consistent results (C.R. Kothari, 2004). Bryman and Bell (2015) define reliability, as the consistency when applied repeatedly under comparable circumstances that an information collection instrument displays. Pre-testing of the instrument was achieved to aid the research study questionnaire's trustworthiness, reliability or consistency. Centered on the results of the pilot research, Cronbach's Alpha measured the internal consistency of the questionnaire items in assessing the questionnaire's reliability. Cronbach's test is a measure of a test scale's consistency or reliability and is expressed as a number between 0 and 1 (Cronbach 1951). According to Sekaran and Bougie (2016), any reliability index greater than 0.7 is taken to represent a satisfactory level of instrument reliability, therefore, the reliability threshold for this study was 0.7 and above.

\section{Results}

From the satellite data presented in Figure 2, it is evident that a lot of rainfall is experienced in the months of December, January and February as well as in the months of March, April and May. Such seasons can be targeted for intensive rain water harvesting to enhance water availability in the households. 


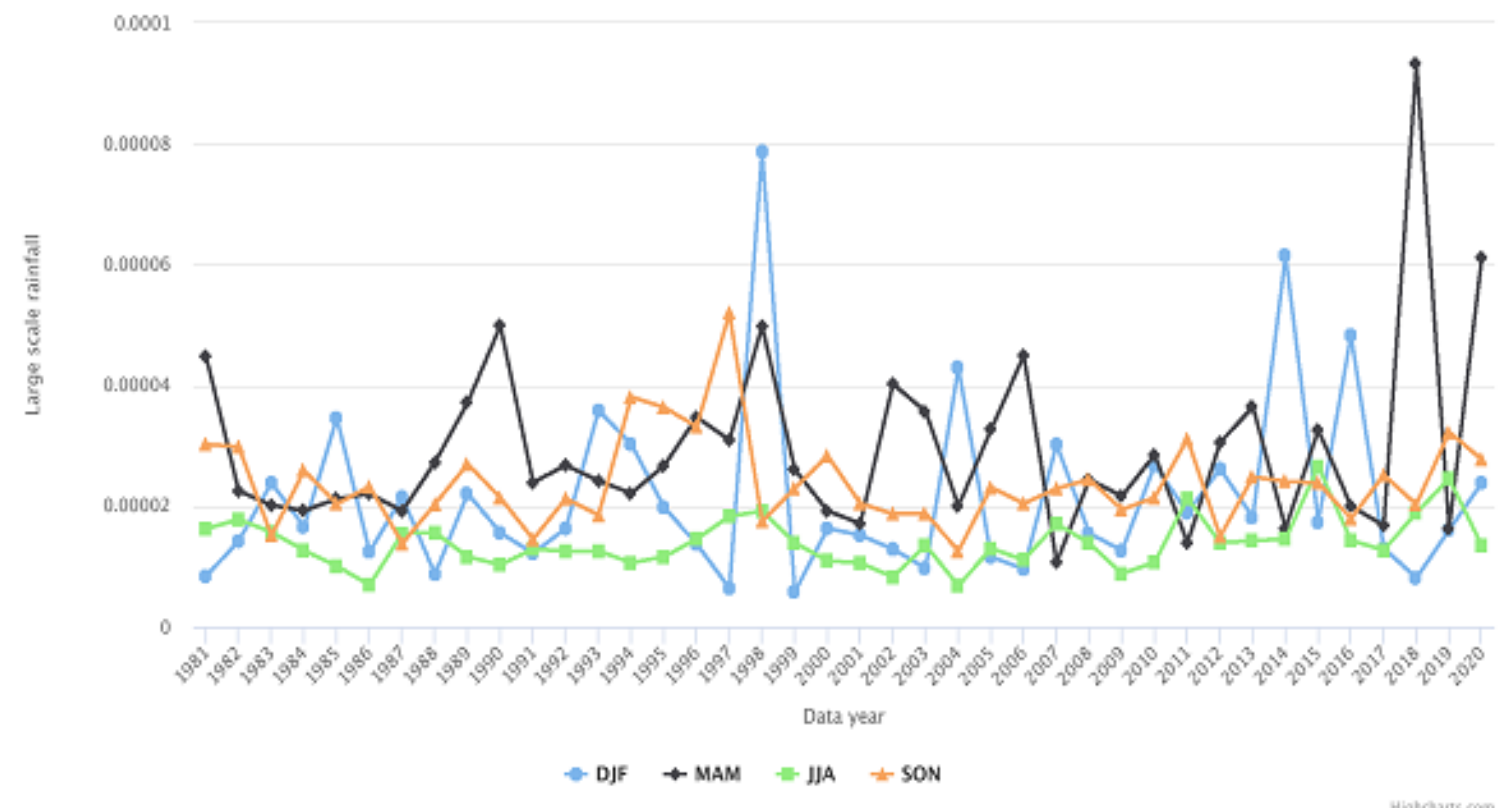

Figure 2. Interannual time series

Study results showed that majority of the respondents at $61 \%$ were male while female represented $39 \%$ of the respondents. This showed that the male gender was higher than the female gender, an indication that the males participated more and appropriately considered in undertaking rain water harvesting technologies than the females. Further, majority of the respondents at $31 \%$ were between ages 18-30 years and $50-90$ years each. $21 \%$ and $17 \%$ of the respondents represented ages $31-40$ years and $41-$ 49 years respectively. This showed a balanced representation of both the youth and the old participation in rain water harvesting activities.

The study outcomes revealed that majority of the respondents at $75 \%$ were farmers, followed by $11 \%$ of the respondents who were self-employed. $8 \%, 4 \%$ and $2 \%$ of the respondents constituted of employed, other not specified and businesspersons respectively. Being a household survey and relevant to the study topic, achieving Table 1: Household Rain Water Technologies
$75 \%$ of farmers as the majority of the respondents gave a good representation towards making of the study conclusions.

From the study findings indicated in Table 1, majority of the respondents at $98 \%$ engaged in household rain water harvesting technologies while only $2 \%$ of the respondents did not. The only issue to note is that even if majority of the respondents engaged in rain water harvesting exercise, the technologies used could only allow for very little water collection for domestic use and for a short period of time. Majority of the respondents harvested rain water in small buckets and small drums. Others harvested rain water using shallow wells and water pans that could only last for a few weeks or months. Such methods were not sustainable and hence the women and young girls in most communities kept walking for long distances in search for water.

\begin{tabular}{lcc}
\hline Household RWT & Frequency & Percent \\
\hline Yes & 371 & 98 \\
No & 8 & 2 \\
Total & 379 & $\mathbf{1 0 0}$ \\
\hline
\end{tabular}




\section{Barriers and enablers of utilizing rain water technologies}

Analysis of barriers and enablers of utilizing rain water harvesting technologies among Households indicated that majority of the respondents at $98 \%$ engaged in household rain water technologies while only $2 \%$ of the respondents did not. This contributed significantly to the achievement of the applicable study information.

Household decision making analysis on rain water technologies showed that majority of the respondents as decision makers in the household were the household heads at $87 \%$. This was far followed by the spouse and self-help group at $4 \%$ each of the respondents. The community and both self and spouse were at 3\% and $2 \%$ of the respondents respectively, while the government was only at $1 \%$ of the respondents. This was a clear indication that most household decision makers were the head of the households. Majority of the respondents with a mean of 4.51 and a standard deviation of 0.980 agreed that county regulations did not support the technology used while a mean of 3.97 and a standard deviation of 0.479 of the respondents agreed that there was lack of expertise to train and guide individuals on the technologies. Again, respondents with a mean of 3.83 and a standard deviation of 0.682 said that there was lack of funds to utilize the technologies. In addition, respondents with means of 1.94 and 1.75 having standard deviations of 1.314 and 1.354 agreed that there was no enough water from other sources other than rain water and decision by the household head did not facilitate use of technologies respectively. Furthermore, The study findings disclosed that majority of the respondents at $93 \%$ said that water scarcity and unavailability motivated them to harvest rain water. $90 \%$ and $88 \%$ of the respondents agreed to the fact that there was water inaccessibility and because of just self-drive and self-initiative. $86 \%$ each of the respondents attributed their motivation to group and community initiatives and to avoid wastage while $85 \%$ of the respondents said that it was for domestic, livestock and irrigation purposes. On the other hand, $23 \%, 11 \%$ and $5 \%$ of the respondents respondents with only a mean of 1.50 and a standard deviation of 1.092 said that beliefs and traditions did not allow household to utilize the technologies.

Overall, a composite mean of 2.92 and a standard deviation of 0.503 implied that all the statements relating to the main barriers that hindered the utilization of RWHTs did significantly impact the households' livelihoods.

\section{Financing use of Rainwater harvesting technologies}

The study findings revealed that majority of the respondents at $86 \%$ said that the head of household was the main source of capital in the purchase of rain water harvesting method while $7 \%$ of the respondents said it was the community. On the other hand, respondents with 5\% said it was carried out by the self-help group while only $1 \%$ each of the respondents agreed it was done by the county government and both self and spouse. This was a clear indication that majority of household heads were the main source of capital towards purchasing the rain water harvesting method.

Considering the level of inclusiveness in the management of rain water harvesting technologies, the study indicated that majority of the respondents at $79 \%$ said that they sometimes practiced level of inclusiveness in the management of RWHTs while $10 \%$ of the respondents said that they often practiced. $6 \%$, $3 \%$ and $2 \%$ of the respondents said that they rarely practiced, had never practiced and extensively practiced level of inclusiveness in the management of RWHTs respectively.

attributed their motivation to reasonably affordable water harvesting technologies, support from the county government and to frequent campaigns from development organizations on water harvesting respectively. Only an insignificant number of respondents at $0.3 \%$ said that there were no funds to put up the system.

The results on the respondents' support for water harvesting programmes showed that majority of the respondents at $85 \%$ said that the head of the household was the one who supported the water 
harvesting programmes mentioned while $9 \%$ of the respondents said it was the community. $4 \%$ of the respondents indicated that the self-help group supported the water harvesting programs mentioned and, only $0.3 \%$ and $0.6 \%$ of the respondents said it was supported by the county government and both self and spouse respectively. Once again, this showed a clear indication that majority of household heads supported the water harvesting programs mentioned which aided in realizing quality answers for the study focus.

The study findings on the level of awareness of rain water harvesting technologies revealed that majority of the respondents at $82 \%$ each agreed that they were aware of shallow wells and sand dams as rain water harvesting technologies while $73 \%$ and $31 \%$ of the respondents said that they knew of roof catchment tanks and water pans rain water harvesting technologies respectively. Only $23 \%$ of the respondents said they were aware of the rock catchments.

Majority of the respondents at $85 \%$ above said that they heard from the radio about the rain water harvesting technology while $29 \%$ and $12 \%$ of the respondents said that they were informed from their self-help group and village barazas respectively. Only 3\% and $1 \%$ of the respondents said they saw from the television and got information from the county government respectively.

Majority of the respondents at $92 \%$ said they harvested rain water while only $2 \%$ did not. This information was very pertinent and vital for this study.

Only 29 respondents out of the total sample of 379 were filtered in these responses, whereby majority of the respondents at $59 \%$ said they did not harvest rain water because they had/used a well/borehole. This was followed by $34 \%$ of the respondents who said they lacked the harvesting technologies. $3 \%$ each of the respondents said it was because they did not know how it was done, there were no funds to put up the system and the roads were made of mad respectively.

Impact of rainwater harvesting on livelihoods

The results revealed that majority of the respondents at $76 \%$ said they used rooftop rainwater harvesting method while $47 \%$ of the respondents said they used the surface rainwater harvesting method. $7 \%$ of the respondents said they used catchments while only $1 \%$ each of the respondents used first flush and filter methods respectively.

\section{Social and economic sustainability}

The majority of the respondents at $85 \%$ indicated that they used the harvested rain water for drinking while $76 \%$ used it for irrigation purposes. Again, 51\% and 32\% of the respondents used the harvested rain water for livestock and domestic purposes respectively. Last but not least, $10 \%$ of the respondents said they sold the harvested rain water.

Among the factors used for impact assessment include: Community initiatives, easy and timely access to water, and availability of safe and quality water for drinking, sufficient water supply and income from quality harvest and animals sale (Figure 3).

Community initiative, Easy and timely access to water and sufficient water supply forms the minimal deviation and hence almost perfect correlation with the livelihood of the community. Therefore amongst the various factors analyzed, the community initiative, easy and timely access to water and sufficiency of water are the main key factors behind the livelihoods sources of the community

Majority of the respondents at $88 \%$ evidently agreed that women and girls saved time for fetching water to other activities. This was followed by $80 \%$ of the respondents who said that they now kept new crops and livestock. $12 \%$ and $10 \%$ of the respondents said that there was increased acreage on crop land and increased number of livestock respectively. Only $3 \%$ of the respondents said that there was enhanced relationship/cohesion with the government and community as a benefit.

The study results revealed that majority of the respondents at $80 \%$ clearly indicated that they used the harvested rain water for domestic purposes while $14 \%$ of the respondents used it for fish farming. In addition, only $4 \%$ and $2 \%$ of the respondents used the harvested rain water for 
horticulture and water venting purposes respectively.

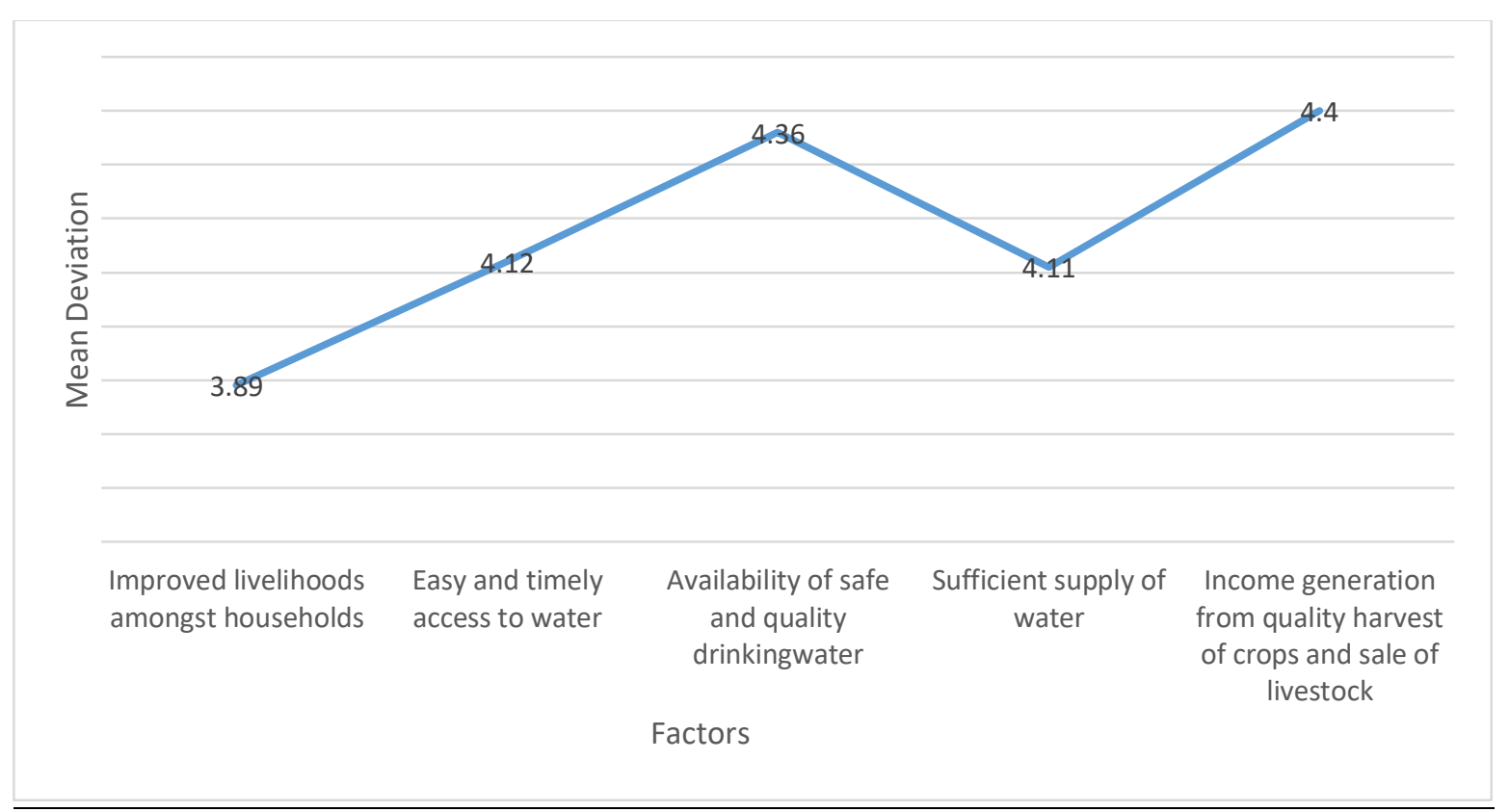

Figure 3. Impact on Household Livelihoods

The study results indicated that majority of the respondents at $58 \%$ said that their main source of water for domestic and other purposes was rainwater while $38 \%$ said they used borehole water. Also, $4 \%$ of the respondents said they used tap water and only $0.3 \%$ used bottled water. Rain water harvesting technologies affect household water availability, affordability and stability. This is because majority of the respondents with a mean of 4.34 and a standard deviation of 1.037 agreed that rain water harvesting technologies affected their household water affordability while a mean of 3.88 and a standard deviation of 0.760 of the respondents agreed that rain water harvesting technologies affected their household water availability. Furthermore, respondents with an individual mean of 3.82 and a standard deviation of 0.956 said that the rain water harvesting technologies affected their household water stability.

Overall, a composite mean of 4.01 and a standard deviation of 0.918 implied that rain water harvesting technologies significantly affected household water availability, affordability and stability.

\section{Food security and higher income}

The study findings in regards to crop production points out that rain water harvesting has led to a major contribution to improving crop production. Supplemental irrigation has provided just enough water to increase rain-fed crops productivity during the dry season or long dry periods between episodes of rain during the rainy season. The social and economic sustainability of rainwater harvesting practices depend largely on the extent of involvement by farmers and the general communities (Vohland, K \& Barry, B (2009). Farmers applying in situ rainwater harvesting practices were seen to benefit from higher food security and higher income (Ibid, 2009). Water availability is the most important consideration for farmers regarding what, when, and how much to plant in a season (Global Water Institute, 2013).

The net income per households differs with the kind of crop produce. As evidence from figure 4, maize crop is the most produce and sold. It has the highest production and sale with a quantity of less than forty thousand kilograms, followed by beans, watermelon, pigeon peas, onions, tomatoes and cabbages. Generally the net income from quantity of sales below forty thousand 
kilograms takes a larger percentage which is in the correspondence to level of production.

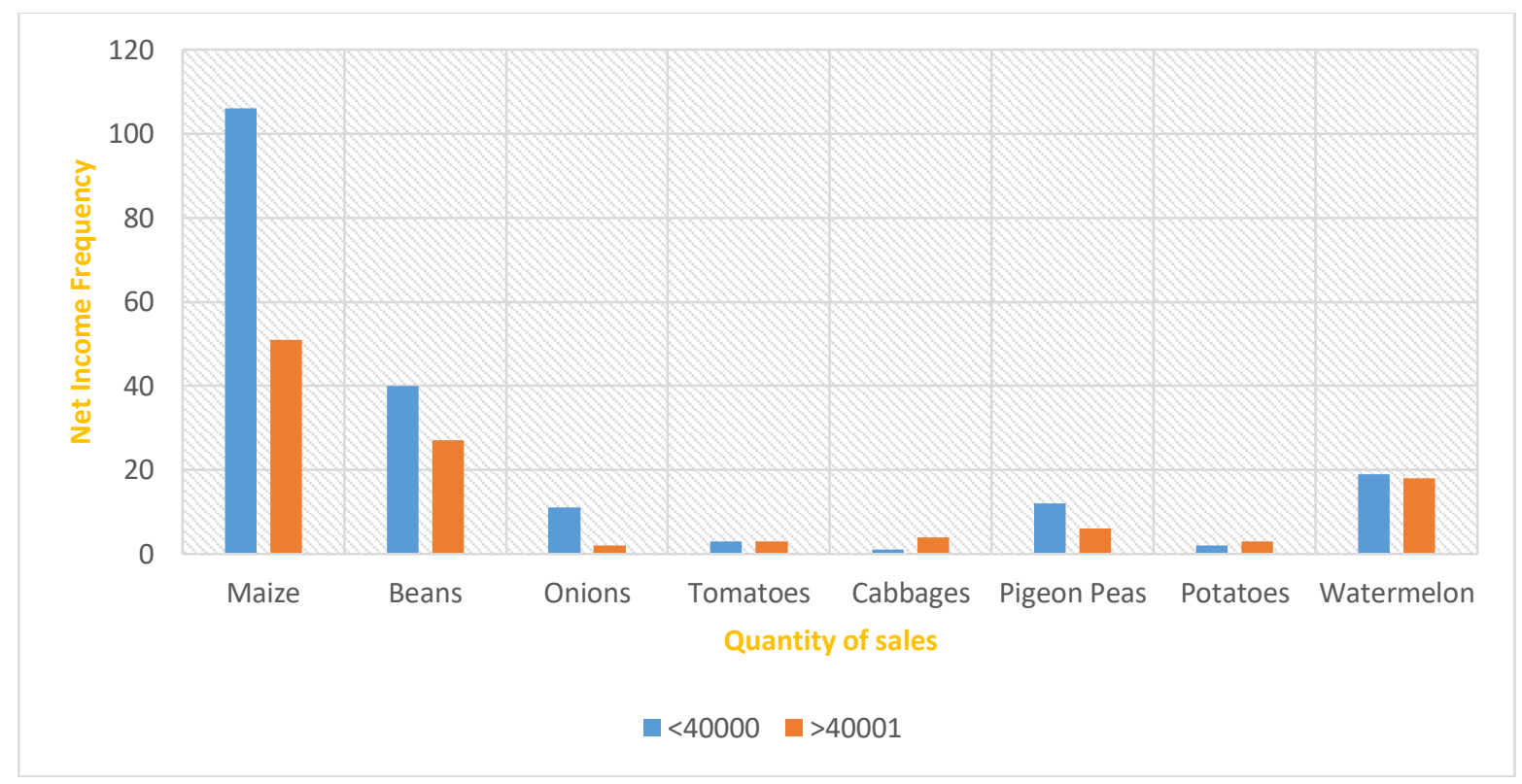

Figure 4. Net income frequency from crops

The study results revealed that majority of the respondents with a mean of 4.46 and a standard deviation of 0.861 agreed that low milk production was the main effect of not harvesting rain water. This was followed by poor livestock health effects with a mean of 4.30 and a standard deviation of 0.822 of the respondents. In addition, a mean of 4.20 and a standard deviation of 0.995 of the respondents agreed that it led to no irrigation of crops while a mean of 3.90 and a standard deviation of 0.582 of the respondents agreed to the effect that they went for long distances to fetch water for domestic use hence loss of man hours. Moreover, means of 3.81 and 3.79 with standard deviations of 0.862 and 0.701 of the respondents agreed that it was expensive to buy water and led to poor crop harvests respectively. Last but not least, a mean of 3.65 and a standard deviation of 0.734 of the respondents agreed that not harvesting rain water led to livestock deaths.

The main challenge faced by the majority of the respondents for lack of enough rain water to harvest was livestock stock reduction at $94 \%$ as seen from table 4.31 above. This was followed by $91 \%$ each of the respondents who attributed this to some crops not being cultivated and reduction of family income. $90 \%$ and $89 \%$ of the respondents said that more family income went to fetching of water and it also resulted to women and children walking long distances in search for water respectively. Again, $87 \%$ and $85 \%$ of the respondents said that it also resulted in reduced crop yields and reduced milk yields respectively. Only $1 \%$ of the respondents said it caused drought.

The study results showed that majority of the respondents with a mean of 4.40 and a standard deviation of 0.815 agreed that income generation from quality harvest of crops and sale of livestock had a strong impact on household livelihoods (Figure 5). Overall, a composite mean of 4.18 and a standard deviation of 0.566 of the respondents agreed that rain water harvesting significantly had an impact on household livelihoods. 


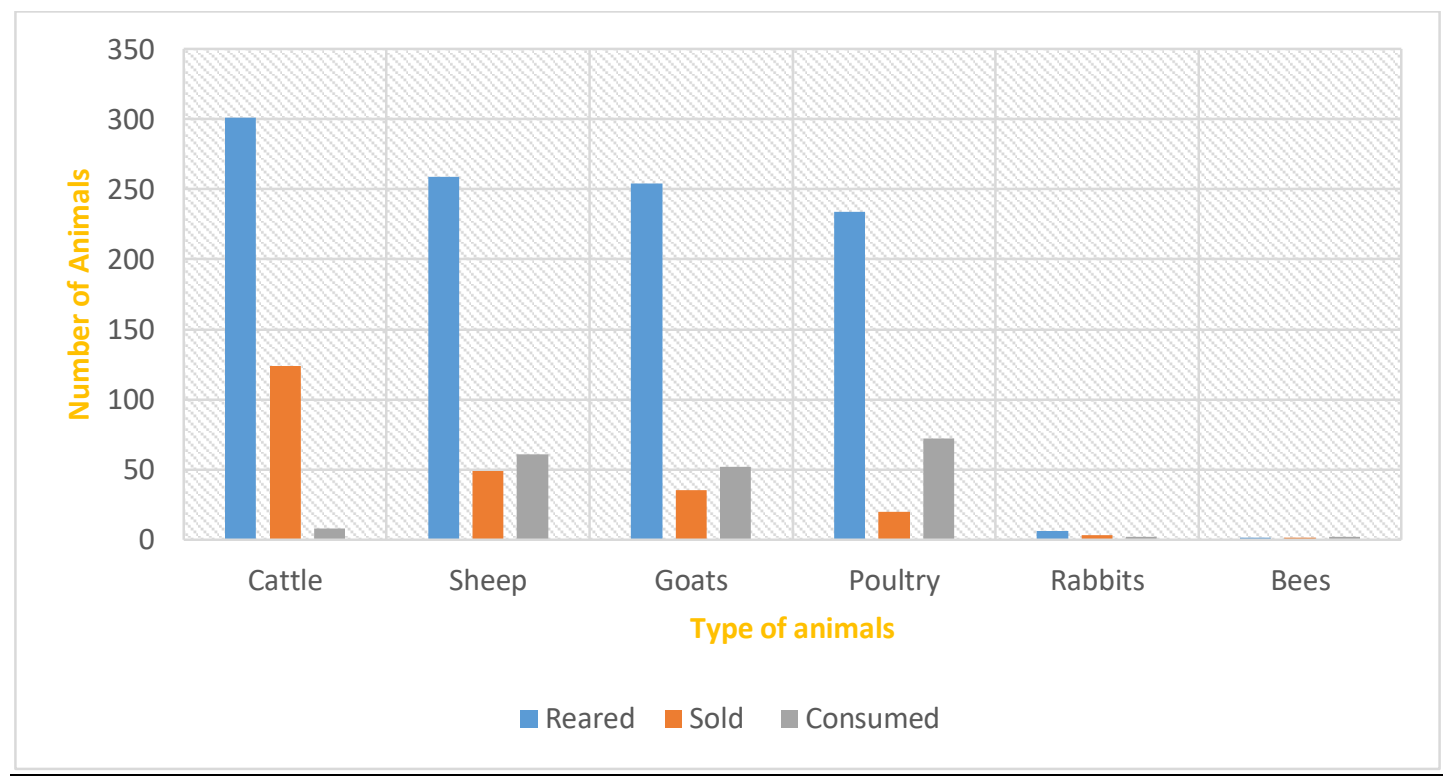

Figure 5. Livestock keeping

The correlation coefficient is a statistical measure of the strength of the relationship between the relative movements of two variables (Akhilesh Ganti and Peter Westfall, 2020). Correlation analysis in this study was to show the strength of relationships between the independent and dependent variable. A high correlation meant that two or more variables had a strong relationship with each other, while a weak correlation meant that the variables were hardly related.

The correlation matrix displayed revealed that there was a positive weak correlation between barriers and enablers, and impact on household livelihoods which implied that a unit increase in barriers and enablers, increases impact on household livelihoods by 0.036 in Nairobi.

The correlation matrix revealed that there was a positive strong and significant correlation between integration of RHT in county development agenda and impact on household livelihoods which implied that a unit increase in integration of RHT in county development agenda increases impact on household livelihoods by 0.755 in Nairobi. 
Table 3. Analysis of Variance of WHT and Impact on Household Livelihoods

\begin{tabular}{lcccc}
\hline \multicolumn{4}{c}{ Model Summary } \\
\hline Model & R & R Square & Adjusted R Square & $\begin{array}{c}\text { Std. Error of the } \\
\text { Estimate }\end{array}$ \\
\hline 1 & $0.703^{\mathrm{a}}$ & 0.495 & 0.493 & 0.403 \\
\hline
\end{tabular}

Predictors: (Constant), Water Harvesting Technologies

Table 4. Model Summary for WHT and Impact on Household Livelihoods

\begin{tabular}{llccccc}
\multicolumn{7}{c}{ ANOVA $^{\mathbf{b}}$} \\
Model & Sum of Squares & df & Mean Square & F & Sig. \\
& & 59.967 & 1 & 59.967 & 368.926 & $0.000^{\text {a }}$ \\
& Regression & 61.280 & 377 & 0.163 & & \\
\multirow{3}{*}{1} & Residual & 121.247 & 378 & & & \\
& Total & &
\end{tabular}

a. Predictors: (Constant), Water Harvesting Technologies

b. Dependent Variable: Impact on Household Livelihoods

Regression analysis technique was used in this study to find out whether the independent variables influenced the dependent variable. Regressions help uncover areas in operations that can be optimized by highlighting trends and relationships between factors (Dana Liberty, 2020). The standardized regression - beta weights (ß) - was used to assess the independent effect of each variable in the regression equation on the dependent variable. The regression model aided in describing how the mean of the dependent variable changes with the changing condition.

The first objective of the study was to assess the barriers and enablers of utilizing rain water harvesting technologies among households in Matungulu Sub-County, Kenya. Simple linear regression model was used to test the hypothesis in order to meet the requirements of the first objective as follows.

$\mathbf{H}_{0}$ : Livelihood differences of households do not significantly influence the effects of rain water harvesting technologies and those without in Matungulu Sub-County, Kenya.

$\mathbf{H}_{1}$ : Livelihood differences of households significantly influence the effects of rain water harvesting technologies and those without in Matungulu Sub-County, Kenya.

Model summary for WHT and impact on household livelihoods
The results showed the model explanatory power between water harvesting technologies and the impact on household livelihoods determined by the ' $R$ square'. This established that $49.5 \%$ of the changes in the impact on household livelihoods can be explained by water harvesting technologies while the remaining percentage of the impact on household livelihoods at $50.5 \%$ can be explained by other factors excluded from the model.

The ANOVA results showed an $\mathrm{F}$ Value of 368.926 reflecting a significance level of $.000^{\text {a }}$ meaning the test statistic is significant at that level. This revealed that water harvesting technologies had a statistical significant impact on household livelihoods at $95 \%$ confidence level.

The results indicated that water harvesting technologies had a positive and statistically significant influence on the impact on household livelihoods $(\beta=$ $0.703, t=19.207, p=0.000<0.05)$. This further implied that a unit change in water harvesting technologies holding other factors constant increases impact on household livelihoods by 0.703 units (Figure 3).

Based on the research findings achieved, we reject the null hypothesis which stated that water harvesting technologies do not significantly influence the effects of rain water harvesting technologies among households. Therefore, 
using the statistical findings, the regression model can be substituted as: $y=1.263+0.703 X_{2}$.

\section{Discussion}

RWH systems aim to minimize seasonal variation in water availability such as droughts and dry spells (Rockström, J., Barron, J., \& Fox, P., 2003). The social and economic sustainability of RWH practices depend largely on the extent of involvement by farmers and the general communities. This might be the weakest link in the chain of sustainability issues (Botha et al., 2004). The more local communities are involved in planning, the higher the possibility that RWH structures will be maintained and benefits are shared (Bangoura, 2002). The study observed that decisions on the use of Rain Water harvesting technologies are influenced by the household head. Other influencers are self-help groups, community and governments. In this case, the county government had the least influence on decisions to use rain water harvesting technologies.

The study identified key barriers to utilization of RWT as; Lack of funds to utilize the technologies, regulations that does not support the technology use and lack of expertise to train and guide on utilization of rain water technologies. This agrees with case studies done by Kim et al., (2016), who found out that the cost of a rainwater harvesting system is economically prohibitive for most individual households. The United Nations (UN) recognizes the need to reduce the number of people that lack sustainable access and utilization of clean water and sanitation (UNEP, 2015). In Kenya, water crisis occurs when there is a situation of inability by the government to supply clean, safe drinking water to its population (UNESCO, 2018).

The study found out that major socio-economic benefits of harvesting rainwater included women and girls saved time for fetching water, increased opportunities for new crops and livestock, increased acreage on crop land, increased number of livestock respectively. This supports the findings by World Health Organization (2019) that improving water storage through improved rainwater harvesting technologies can enable communities to spend less time and the effort of physically collecting it, and thus communities can be productive in other ways. This can also result in greater personal safety by reducing the need to make long or risky journeys to collect water, less expenditure on health, communities can remain economically productive. This is further depicted in this study with findings suggesting that rain water harvesting technologies affect household water availability, affordability and stability. This is because majority of the respondents with a mean of 4.34 and a standard deviation of 1.037 agreed that rain water harvesting technologies affected their household water affordability while a mean of 3.88 and a standard deviation of 0.760 of the respondents agreed that rain water harvesting technologies affected their household water availability. Overall, a composite mean of 4.01 and a standard deviation of 0.918 implied that rain water harvesting technologies significantly affected household water availability, affordability and stability.

Availability of water for irrigation has also significantly increased the household income. The study findings suggest that rain water harvesting has led to a major contribution to improving crop production. Supplemental irrigation has provided just enough water to increase rain-fed crops productivity during the dry season or long dry periods between episodes of rain during the rainy season. This supports the findings of Rockström, J., Barron, J., \& Fox, P. (2003) who found out that under erratic rainfall conditions in the semi-arid zone of sub-Saharan Africa, a major contribution to improving crop production can be anticipated from improved and up-scaled SWC and RWH conservation practices.

Table 2 shows the findings of the crop production and its use, comparing domestic use and sales. These findings suggest that where there is a surplus, households are able to earn income from sale of farm produce. This confirms the findings UNEP, (2015) that improving water management improves or enhances national economies, rural agriculture and other food sectors. These make them more resilient to variances in rainfall and thus they are able to fulfill the needs of their households' growing population 
Table 2. Crops Production, Sales and Home Consumption

\begin{tabular}{|c|c|c|c|c|c|c|c|c|c|}
\hline \multirow{2}{*}{ Crops Grown } & & \multicolumn{2}{|c|}{$\begin{array}{l}\text { No. of KGs } \\
\text { Produced }\end{array}$} & \multicolumn{2}{|c|}{ Sale Price Per KG } & \multicolumn{2}{|c|}{ KGs Sold } & \multicolumn{2}{|c|}{$\begin{array}{c}\text { KGs Used at } \\
\text { Home }\end{array}$} \\
\hline & & $<1000$ & $>1001$ & $<50$ & $>51$ & $<1000$ & $>1001$ & $<200$ & $>201$ \\
\hline \multirow{2}{*}{ Maize } & $\mathbf{f}$ & 236 & 71 & 149 & 9 & 117 & 45 & 225 & 62 \\
\hline & $\%$ & 77 & 23 & 94 & 6 & 72 & 28 & 78 & 22 \\
\hline \multirow{3}{*}{ Beans } & $\mathbf{f}$ & 254 & 12 & 4 & 64 & 60 & 12 & 220 & 34 \\
\hline & & & & & & & & & \\
\hline & $\%$ & 95 & 5 & 6 & 94 & 83 & 17 & 87 & 13 \\
\hline \multirow{2}{*}{ Onions } & $\mathbf{f}$ & 34 & 2 & 14 & 1 & 13 & 2 & 32 & 2 \\
\hline & $0 \%$ & 94 & 6 & 93 & 7 & 87 & 13 & 94 & 6 \\
\hline \multirow{3}{*}{ Tomatoes } & $\mathbf{f}$ & 17 & 3 & 5 & 3 & 5 & 8 & 17 & 2 \\
\hline & & & & & & & & & \\
\hline & $\%$ & 85 & 15 & 63 & 38 & 63 & 37 & 89 & 11 \\
\hline \multirow{3}{*}{ Kales } & $\mathbf{f}$ & 6 & - & - & - & - & - & 6 & - \\
\hline & & & & & & & & & \\
\hline & $\%$ & 100 & - & - & - & - & - & 100 & - \\
\hline \multirow{3}{*}{ Cabbages } & $\mathbf{f}$ & 4 & 3 & 5 & - & 2 & 3 & 5 & 2 \\
\hline & & & & & & & & & \\
\hline & $\%$ & 57 & 43 & 100 & - & 40 & 60 & 71 & 29 \\
\hline \multirow{3}{*}{ Pigeon Peas } & $\mathbf{f}$ & 179 & 3 & 1 & 17 & 17 & 3 & 162 & 16 \\
\hline & & & & & & & & & \\
\hline & $\%$ & 98 & 2 & 6 & 94 & 85 & 15 & 91 & 9 \\
\hline \multirow{3}{*}{ Potatoes } & $\mathbf{f}$ & 4 & 3 & 1 & 4 & 3 & 2 & 5 & 2 \\
\hline & & & & & & & & & \\
\hline & $\%$ & 57 & 43 & 20 & 80 & 60 & 40 & 71 & 29 \\
\hline \multirow{3}{*}{ Watermelon } & $\mathbf{f}$ & 2 & 36 & 2 & 35 & 7 & 30 & 13 & 23 \\
\hline & & & & & & & & & \\
\hline & $\%$ & 5 & 95 & 5 & 95 & 19 & 81 & 36 & 64 \\
\hline
\end{tabular}

Livestock production is also positively affected by availability of water from rainwater harvesting. The study results suggest that household benefit from increased milk production as well as general livestock profitability. Table 3 Summarizes the study results based on the benefits accrued from availability of water for livestock. This confirms 
the findings of Ibid (2009) that rainwater harvesting practices improve hydrological indicators such as infiltration and groundwater recharge. Soil nutrients were seen to be enriched. Biomass production increased, with subsequent higher yields. He further states that higher biomass was noted to have supported a higher number of plants and animals. He concluded that farmers applying rainwater harvesting practices were seen to benefit from higher food security and higher income.

Table 3. Livestock Reared, Sale and Home Consumption

\begin{tabular}{|c|c|c|c|c|c|c|c|c|c|c|}
\hline \multirow{2}{*}{$\begin{array}{c}\text { Livestock } \\
\text { Reared }\end{array}$} & & \multicolumn{2}{|c|}{ No. Reared } & \multicolumn{2}{|c|}{ No. Sold } & \multicolumn{2}{|c|}{$\begin{array}{l}\text { No. Consumed } \\
\text { at Home }\end{array}$} & \multicolumn{3}{|c|}{$\begin{array}{l}\text { Sale Price Per KG or Whole } \\
\text { in Kenya Shillings }\end{array}$} \\
\hline & & $<10$ & $>11$ & $<10$ & $>11$ & $<10$ & $>11$ & $<500$ & $501-3000$ & $>3001$ \\
\hline \multirow{2}{*}{ Cattle } & f & 206 & 95 & 114 & 10 & 7 & 1 & 2 & 3 & 119 \\
\hline & $\%$ & 68 & 32 & 92 & 8 & 88 & 12 & 2 & 2 & 96 \\
\hline \multirow{2}{*}{ Sheep } & f & 218 & 41 & 44 & 5 & 58 & 3 & 1 & 4 & 41 \\
\hline & $\%$ & 84 & 16 & 90 & 10 & 95 & 5 & 2 & 9 & 89 \\
\hline \multirow{3}{*}{ Goats } & $\mathrm{f}$ & 220 & 34 & 32 & 3 & 51 & 1 & 1 & - & 32 \\
\hline & & & & & & & & & & \\
\hline & $\%$ & 87 & 13 & 91 & 9 & 98 & 2 & 3 & - & 97 \\
\hline \multirow{3}{*}{ Poultry } & $\mathrm{f}$ & 181 & 53 & 9 & 11 & 58 & 14 & 11 & 7 & - \\
\hline & & & & & & & & & & \\
\hline & $\%$ & 77 & 23 & 45 & 55 & 81 & 19 & 61 & 39 & - \\
\hline \multirow{3}{*}{ Rabbits } & f & 2 & 4 & - & 3 & 1 & 1 & - & 3 & - \\
\hline & & & & & & & & & & \\
\hline & $\%$ & 33 & 67 & - & 100 & 50 & 50 & - & 100 & - \\
\hline \multirow{3}{*}{ Bees } & f & - & 1 & - & 1 & 2 & - & 1 & - & - \\
\hline & & & & & & & & & & \\
\hline & $\%$ & - & 100 & - & 100 & 100 & - & 100 & - & - \\
\hline
\end{tabular}

The study identified key areas of benefits of rainwater harvesting as reduced distance for sourcing water From the study's regression analysis, the study indicated that barriers and enablers had a positive but statistically insignificant influence on the impact on household livelihoods $(\beta=0.036, t=0.700$, $\mathrm{p}=0.484>0.05)$ therefore, we accepted the null hypothesis which stated that barriers and enablers do not significantly influence the effects of rain water harvesting technologies among households. On the other hand, water harvesting technologies had a positive and statistically significant influence on the impact on household livelihoods $(\beta=0.703, t=19.207, p=0.000<0.05)$ hence, we rejected the null hypothesis which stated that water harvesting technologies do not significantly influence the effects of rain water harvesting technologies among households. 


\section{Conclusion}

Water harvesting technologies had a statistically significant influence on the impact on household livelihoods. It was established that a number of rainwater harvesting technologies had been utilized by several households in the study area as a way of supplementing rain-fed agriculture. Moreover, Integration of RHT in County Development Agenda was also considered to have a statistically significant influence on the impact on household livelihoods Majority of the respondents agreed that rain water harvesting significantly impacted household livelihoods.

RWH technologies improves agricultural production and enhances rural households' standard of living, improves household income and reduces environmental degradation. There is therefore, need to create awareness amongst communities, sensitize them and even develop

\section{References}

Akhilesh, G., Westfall P., (2020, October 12). Investopedia, Financial Analysis: Correlation Coefficient. https://www.investopedia.com/terms Lc/correlationcoefficient.asp

Angoua, E. L. E., Dongo, K., Templeton, M. R., Zinsstag, J., \& Bonfoh, B. (2018). Barriers to access improved water and sanitation in poor peri-urban settlements of Abidjan, Côte d'Ivoire. PloS one, 13(8), e0202928

Armah, F. A., Ekumah, B., Yawson, D. O., Odoi, J. O., Afitiri, A. R., \& Nyieku, F. E. (2018). Access to improved water and sanitation in sub-Saharan Africa in a quarter century. Heliyon, 4(11), e00931.

Baldwin, E., McCord, P., Dell'Angelo, J., \& Evans, T. (2018). Collective action in a polycentric water governance system. Environmental Policy and Governance, 28(4), 212-222.

Bancy, M., Tanguy, D. B., Maimbo, M., Khaka, E., Oduor, E., Nyabenge, M., Oduor, V., 2007.

Bangoura, S. (2002). Private irrigation development in support of food security short training sessions to enlighten farmers and rural communities on the adoption of rainwater harvesting technologies.

\section{Acknowledgement}

The authors appreciate the contributions of Dr. Bessy Kathambi, Lillian Sarah Namuma Kong'ani, Rosemary Kadali, Francis Kimweli Nzomo, Dr. Christine Mbindyo and Anne Arochi for the great assistance they offered while I was undertaking my research.

\section{Authors' contributions}

The three authors listed made substantial, direct and intellectual contributions to the work, and approved it for publication.

\section{Conflict of Interest}

The authors declare that the research was conducted in the absence of any commercial or financial relationships that could be construed as a potential conflict of interest.

in West Africa. In Le Centre technique de coopération agricole et rurale (CTA) a été créé en 1983 dans le cadre de la Convention de Lomé entre les États du groupe ACP (Afrique, Caraibes, Pacifique) et les pays membres de l'Union européenne. Depuis 2000, le CTA exerce ses activités dans le cadre de l'Accord de Cotonou ACP-EU. (p. 15).

Mapping the Potential of Rainwater Harvesting Technologies in Africa: A GIS overview and atlas of development domains for the continent and ten selected countries. United Nations Environmental Programme (UNEP) World Agro forestry Centre (ICRAF)

Barry, B., Olaleye, A. O., Zougmoré, R., \& Fatondji, D. (2009). Rainwater harvesting technologies in the Sahelian zone of West Africa and the potential for outscaling (Vol. 126). IWMI.

Biswas, A. K., \& Tortajada, C. (2019). Water quality management: a globally neglected issue.

Bryan, E., Bernier, Q., Espinal, M., \& Ringler, C. (2018). Making climate change adaptation 
programmes in sub-Saharan Africa more gender responsive: insights from implementing organizations on the barriers and opportunities. Climate and Development, 10(5), 417-431.

Bryman, A., \& Bell, E. (2015). Business research methods (Vol. 4th). Glasgow: Bell \& Bain Ltd.

Carrión-Crespo, C. R. (2010). Green jobs, social dialogue and participatory governance for sustainable water policy reforms.

Cherunya, P. C., Janezic, C., \& Leuchner, M. (2015). Sustainable supply of safe drinking water for underserved households in Kenya: investigating the viability of decentralized solutions. Water, 7(10), 5437-5457.

Cosgrove, W. J., \& Loucks, D. P. (2015). Water management: Current and future challenges and research directions. Water Resources Research, 51(6), 4823-4839.

Cronbach, L. J., 1951. Coefficient Alpha and the Internal Structure of Tests. Psychometrika, 16(3), 297-334.

Global Water Institute, 2013. Without Strategic Water Security, Farmers Will Migrate in Search for Wetter Lands. Retrieved on December 12, 2020 from: www.gwiwater.org

Helmreich, H., Horn, H., 2009. Opportunities in rainwater harvesting: Presented at the Water and Sanitation in International Development and Disaster Relief (WSIDDR) International Workshop Edinburgh, Scotland, UK, 28-30 May 2008.

Kerchof, C. Unlocking the Sustainable Potential of Land Resources: Tools and References from the International Resource Panel Report 2016.

Kim, Y., Han, M., Kabubi, J., Sohn, H. G., \& Nguyen, D. C. (2016). Community-based rainwater harvesting (CB-RWH) to supply drinking water in developing countries: lessons learned from case studies in Africa and Asia. Water Science and Technology: Water Supply, 16(4), 11101121.

Kothari, C.R., 2004. Research Methodology Methods and Techniques, (Second Revised Edition).
Machakos County Integrated Development Plan, (2015). Retrieved on 28th August, 2019, from www.machakosgovernment.com

Pradhan, R., \& Sahoo, J. (2019). Smart Rainwater Management: New Technologies and Innovation. In Smart Urban Development. IntechOpen.

Rockström, J., Barron, J., \& Fox, P. (2003). Water productivity in rain-fed agriculture: challenges and opportunities for smallholder farmers in drought-prone tropical agroecosystems. Water productivity in agriculture: Limits and opportunities for improvement, 85199(669), 8.

Sekaran, U., \& Bougie, R., 2016. Research methods for business: A Skilled Building Approach (7th Ed.). New York: John Wiley \& Sons.

Tamagnone, P., Comino, E., \& Rosso, M. (2020). Rainwater harvesting techniques as an adaptation strategy for flood mitigation. Journal of Hydrology, 586, 124880.

United Nations Development Programme, 2006. Human Development Report 2006: Beyond Scarcity-Power, Poverty and the Global Water Crisis. Basingstoke, United Kingdom: Palgrave Macmillan.

United Nations, 2015. Transforming Our World: The 2030 Agenda for Sustainable Development (A/RES/70/I) Available online at:

Hppts://sustainabledevelopment.un.or $\mathrm{g} /$ content/documents/21252030

Agenda for Sustainable Development web.pdf.

UNEP (2015). United Nations Environmental Programme Annual Report 2015.

UNESCO (2018). UN World Water Development Report, Nature-based Solutions for Water. Retrieved on $10^{\text {th }}$ September, 2019, from:

United States Agency for International Development (USAID) (2014). USAID Family Farming Program - Quarterly Report: Year Four - First Quarter. Unpu blished document, pp. 1-46. Washington, DC: USAID.

Vohland, K \& Barry, B (2009) A Review of In situ rainwater harvesting $(\mathrm{RWH})$ practices modifying 
landscape functions in African drylands, Agricultural Ecosystems and Environment, Vol.131, Pp.119127

World Health Organization. (2019). National systems to support drinking-water: sanitation and hygiene: global status report 2019: UN-Water global analysis and assessment of sanitation and drinking-water: GLAAS 2019 report. 